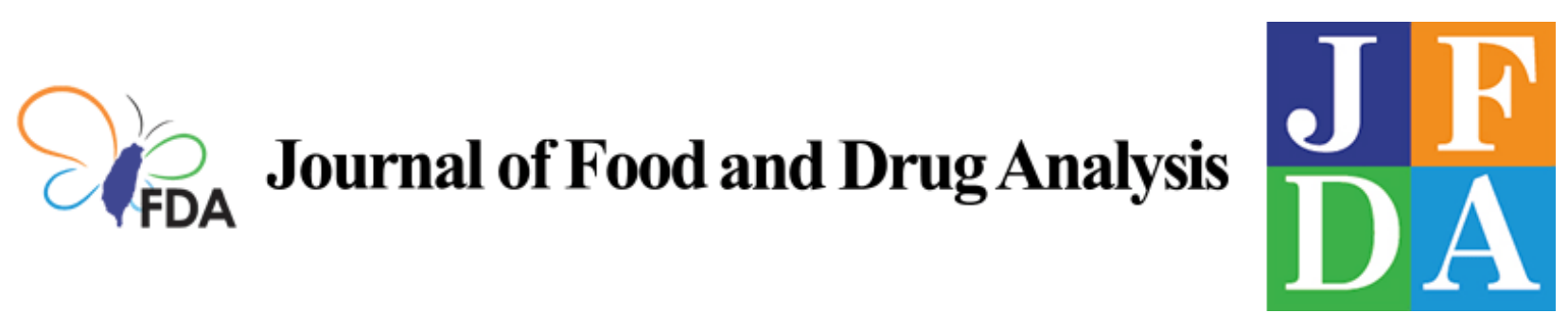

Volume 29 | Issue 3

Article 8

2021

\title{
Determination of cannabinoids in hemp oil based cosmetic products by LC-tandem MS
}

Follow this and additional works at: https://www.jfda-online.com/journal

Part of the Food Science Commons, Medicinal Chemistry and Pharmaceutics Commons, Pharmacology Commons, and the Toxicology Commons

(c) (i) (9)

This work is licensed under a Creative Commons Attribution-Noncommercial-No Derivative Works 4.0 License.

\section{Recommended Citation}

Hsu, Yun-Hua; Fang, Ming-Chih; Huang, Shou-Chieh; Kao, Ya-Min; Tseng, Su-Hsiang; and Wang, Der-Yuan (2021) "Determination of cannabinoids in hemp oil based cosmetic products by LC-tandem MS," Journal of Food and Drug Analysis: Vol. 29 : Iss. 3 , Article 8.

Available at: https://doi.org/10.38212/2224-6614.3370

This Original Article is brought to you for free and open access by Journal of Food and Drug Analysis. It has been accepted for inclusion in Journal of Food and Drug Analysis by an authorized editor of Journal of Food and Drug Analysis. 


\title{
Determination of cannabinoids in hemp oil based cosmetic products by LC-tandem MS
}

\author{
Yun-Hua Hsu ${ }^{a}{ }^{*}$, Ming-Chih Fang ${ }^{b}$, Shou-Chieh Huang ${ }^{a}$, Ya-Min Kao ${ }^{\text {, }}$ \\ Su-Hsiang Tseng ${ }^{a}$, Der-Yuan Wang ${ }^{a}$ \\ a Food and Drug Administration, Ministry of Health and Welfare, Executive Yuan, 161-2 Kunyang St., Nangang Dist., Taipei 11561, \\ Taiwan \\ ${ }^{\mathrm{b}}$ Department of Food Science, National Taiwan Ocean University, Keelung, Taiwan
}

\begin{abstract}
Cosmetic products containing hemp seed oil as permitted raw materials required the specific compound delta-9tetrahydrocannabinol (THC) below $10 \mu \mathrm{g} / \mathrm{g}$. THC was the main psychoactive constituent of cannabis. Since hemp seed oil became an increasingly popular ingredient in cosmetics over the last few years, an efficient and reliable analytical method for THC and other cannabinoids in cannabis-infused cosmetic products was in need. A liquid chromatographytandem mass spectrometry (LC-MS/MS) method for the determination of delta-9-tetrahydrocannabinol (THC), cannabidiol (CBD), and cannabinol (CBN) in hemp seed oil based cosmetic products was developed. Method validation was performed by fertilizing blank samples with analytes and internal standards (THC- $d_{3}, C B D-d_{3}$, and CBN- $d_{3}$ ). Chromatographic method utilized a Xbridge BEH Shield RP18 column with gradient elution containing $10 \mathrm{mM}$ ammonium formate in water and methanol provided successful separation of THC, CBD, and CBN in cosmetic matrix. The combination of MS detection in positive electrospray ionization (ESI) and multiple reaction monitoring (MRM) mode offered rapid run time 13 minutes with limit of quantification (LOQ) of $0.05 \mu \mathrm{g} / \mathrm{g}$. The intra- and inter-day recoveries were $79.23-114.04 \%$ and $83.55-111.61 \%$ with spiking levels ranged between $0.05 \mu \mathrm{g} / \mathrm{g}$ and $0.5 \mu \mathrm{g} / \mathrm{g}$, respectively. Surveillance results of 90 cosmetic products showed 22, 34, and 5 products containing THC (0.06-1777 $\mu \mathrm{g} / \mathrm{g})$, CBD (0.47$37217 \mu \mathrm{g} / \mathrm{g})$, and CBN (2.2-25.2 $\mu \mathrm{g} / \mathrm{g})$, respectively. This validated method offered accurate, reliable, and fast way for the determination of drug contaminations including THC, CBD, and CBN in cosmetics. The surveillance results for commercial cosmetic products purchased in Taiwan between 2018-2020 provided valuable background references for THC, CBD, and CBN in hemp seed oil based cosmetic products, and could be used for administration purpose.
\end{abstract}

Keywords: Cannabidiol, Cannabinol, Cosmetics, Tetrahydrocannabinol

\section{Introduction}

$\mathrm{T}$ he term "hemp", or industrial hemp, is a variety of the Cannabis sativa plant species that is grown specifically for industrial use [1]. It can be refined into a variety of commercial items, including paper, rope, textiles, clothing, biofuel, food, and animal feed. These products require not more than 0.3 percent psychoactive component THC in general. However, the legality of industrial hemp varies widely between countries. Some area regulates THC and permits only hemp that is bred with an especially low THC content [1]. By contrast, another plant similar to hemp called "marijuana" or "weed" refers to the dried leaves, flowers, stems, and seeds from the Cannabis sativa or Cannabis indica plant, contained 5-20\% THC was prohibited.

Hemp seed oil, obtained from the seed of Cannabis sativa L., is a naturally rich source of high quality protein and essential polyunsaturated fatty acids including omega-6 and omega-3 [2]. The health benefits of hemp seed oil are attributed mainly to its desirable omega-3 and omega- 6 fatty acid ratio, 3:1,

Received 9 March 2021; revised 1 June 2021; accepted 30 June 2021.

Available online 15 September 2021.

* Corresponding author: Food and Drug Administration, Ministry of Health and Welfare, Executive Yuan, 161-2 Kunyang St., Taipei 11561, Taiwan. Fax: 886226531764 .

E-mail address: soundings@fda.gov.tw (Y-H. Hsu). 
which is suggested as being optimal for human nutrition [3-5]. This unique composition of hemp seed oil differs from the other common seed oils and offers opportunities for the development of special nutritional formulations, personal care products, and cosmetics such as soap, lotion, shampoos and lipsticks [3,6-8]. Studies suggested that hemp seed and its oil may benefit skin disorders, improve itchiness, and reduce irritation [9, 10]. In recent years, researchers have also investigated its use for anti-inflammatory properties [11, 12]. The advantages to hair such as hair growth, and prevention of dry, split ends, and breakage were reported [13].

Nowadays, cosmetic regulatory compliance of cannabis-derived ingredients as plant extracts, and does not prohibit or restrict the use of them in cosmetics. However, the amounts of $\Delta 9$-tetrahydrocannabinol (THC) and cannabidiol (CBD) are strictly regulated and limited. THC is the major psychoactive component of Cannabis sativa L. and may cause central nerve system disorders. In addition to THC, hemp seed oil contains many other minor cannabinoids including CBD and CBN. CBD is the second highest component in Cannabis sativa L., and accounts for up to $40 \%$ of the plant's extract [14]. CBN was an oxidation byproduct of THC and was the first identified cannabinoid and commonly found in aged cannabis materials. Although CBN was not produced by the metabolism of the plant, it was easily formed from THC by degradation during drying, storing, and consumption (heating) of cannabis products. As a result, it may play a significant role in quality control attributed to Cannabis utilization. The commonly used detection methods for cannabinoids were gas chromatography-mass spectrometry (GC-MS) [15], HPLC-PDA [16], HPLCfluorescence, and liquid chromatography-mass spectrometry (LC-MS/MS) [16-19]. Most of them used for forensic analysis of hair [18], blood [20], urine [21], and oral fluid [17], while others focused on natural products such as hemp seed oil [16] and herbal products [19], only a few were interested in cosmetics [22]. Cosmetic products contained high oils, surfactants, and oil-in-water emulsions, which made sample preparation difficult. Solvent system such as hexane, ethyl acetate, isopropyl alcohol, acetonitrile, methanol along with liquid-liquid extraction were developed for testing water or oil based samples [17-20, 22]. Solid phase extraction (SPE) may be applied to remove phospholipids (PLs) in blood samples [20].

This study aimed on the rapid determination of cannabinoids such as THC, CBD, and CBN in hemp seed oil based cosmetic products. A relatively high polarity solvent, methanol, was selected and tested for rapid sample preparation without further SPE purification. In this respect, multiple matrices were investigated including lotion, cream, essential oil, shampoo, hair colorant, shower gel, and lipstick products. A surveillance study consisted with 90 commercial cosmetics demonstrated the relationship between cannabinoid contents and product types was discussed.

\section{Materials and methods}

\subsection{Chemicals, reagents and samples}

$\Delta^{9}$-Tetrahydrocannabinol (THC, $1 \mathrm{mg} / \mathrm{mL}$ in methanol), cannabidiol (CBD, $1 \mathrm{mg} / \mathrm{mL}$ in methanol), cannabinol (CBN, $1 \mathrm{mg} / \mathrm{mL}$ in methanol), $\Delta^{9}$ tetrahydrocannabinol- $\mathrm{d}_{3} \quad\left(\mathrm{THC}^{-} \mathrm{d}_{3}, 0.1 \mathrm{mg} / \mathrm{mL}\right.$ in methanol), cannabidiol- $\mathrm{d}_{3}\left(\mathrm{CBD}-\mathrm{d}_{3}, 0.1 \mathrm{mg} / \mathrm{mL}\right.$ in methanol), and cannabinol- $\mathrm{d}_{3}\left(\mathrm{CBN}-\mathrm{d}_{3}, 0.1 \mathrm{mg} / \mathrm{mL}\right.$ in methanol) were purchased from Sigma Aldrich (St. Louis, MO, USA). Hemp seed oil based cosmetic products were either purchased from local market or supported from customs and prosecution.

\subsection{Sample preparation}

Cosmetic samples were homogenized, and then $0.2 \mathrm{~g}$ each was accurately weighed into a $10-\mathrm{mL}$ volumetric flask. The flask was added approximately $8 \mathrm{~mL}$ methanol as extraction solvent and $25 \mu \mathrm{L}$ of the internal standards (IS) mixed solution $(10 \mu \mathrm{g} / \mathrm{mL}$ each in methanol). Analytes was extracted by ultrasound-assisted extraction with methanol for $30 \mathrm{~min}$. The sample was dilute with methanol to $10 \mathrm{~mL}$, filtered through a $0.22 \mu \mathrm{m}$ PTFE membrane prior to LC-MS/MS analysis.

\subsection{Separation and detection}

Chromatographic separation was performed using ACQUITY UPLC H-Class system (Waters Corp., Milford, MA, USA) and a Xbridge BEH Shield RP18 column $(3.0 \mathrm{~mm} \times 100 \mathrm{~mm}, 2.5 \mu \mathrm{m}$ particle size, Waters) at flow rate of $0.6 \mathrm{~mL} / \mathrm{min}$. The column was kept at $40^{\circ} \mathrm{C}$ and the sample was maintained at $15^{\circ} \mathrm{C}$. The mobile phase of the LC system consisted of $10 \mathrm{mM}$ ammonia formate buffer (A) and $10 \mathrm{mM}$ ammonia formate in methanol (B). Linearly gradient was programed as follows: 0$5 \mathrm{~min}, 80 \%$ B; $5-6 \mathrm{~min}, 80-100 \%$ B; $6-8 \mathrm{~min}, 100 \% \mathrm{~B}$; 8-8.1 min, $100-80 \%$ B; $8.1-13 \mathrm{~min}, 80 \%$ B. The sample injection volume was $3 \mu \mathrm{L}$. MS detection was performed by a Xevo TQ-XS triple quadrupole mass spectrometer (Waters) at positive electrospray ionization. Multiple reaction monitoring (MRM) 
parameters of $\mathrm{THC}, \mathrm{CBD}$, and $\mathrm{CBN}$ were listed as Table 1.

\subsection{Method validation}

\subsubsection{Limits of quantification (LOQs)}

Blank cosmetic samples were spiked with selected concentrations of THC, CBD, and CBN at 5, 10, 20, 25, 50, and $100 \mathrm{ng} / \mathrm{g}$. Limit of quantification (LOQ) was evaluated by measuring the lowest concentration level in spiked samples while the signal-tonoise ratios were least 10:1 or higher for quantification ions.

\subsubsection{Linearity of calibration}

Triplicate six-point calibration curves with concentration ranging from $1-50 \mathrm{ng} / \mathrm{mL}$ for $\mathrm{THC}, \mathrm{CBD}$, and CBN were prepared in methanol and fitted with a weighted (1/concentration) linear equation. The correlation of coefficient ( $\mathrm{r}$ ) should be above 0.99 . For quantitative applications, individual standards should not deviate by more than $20 \%$ from the nominal value.

\subsubsection{Accuracy and precision}

A total of five replicate quality control (QC) samples at each of 4 different concentrations $(50,100$, 250, $500 \mathrm{ng} / \mathrm{g}$ ) in five different matrices (lotion, essential oil, shampoo, shower gel, and lip balm) were tested for intra-day and inter-day precision and accuracy. Inter-day studies were tested on three different dates. The requirement of repeatability precision of intra-day results must be within $15-20 \%$ coefficient of variation $(\mathrm{CV})$ of the nominal value, and intermediate precision must within $18-22 \% \mathrm{CV}$.

\subsubsection{Matrix effects and recovery studies}

Matrix effects were measured by comparing the peak area of analytes in spiked sample extracts and in solvent. The percentage provided information about ion suppression or enhancement caused by cosmetic matrices. Sample type for matrix effect evaluation included lotion, essential oil, shampoo, shower gel and lip balm. For each compound, four concentrations $(50,100,250,500 \mathrm{ng} / \mathrm{g})$ were tested with triplicates. Recoveries were calculated by comparing the mean peak areas of analytes in blank matrix and in solvent. Besides, internal standard method with isotopically labeled internal standards, THC $-\mathrm{d}_{3}, C B D-\mathrm{d}_{3}$, and CBN- $\mathrm{d}_{3}$ was also evaluated. The acceptable recoveries should be within $75-120 \%$ and precision must not exceed $10 \% \mathrm{CV}$.

\subsection{Surveillance of $T H C, C B D$, and $C B N$ in cosmetics}

Eighty-three samples were detained from customs and prosecutors. Seven samples were purchased from local department stores and drugstores. Sample types included lotions, creams, serums, essential oil, shampoos, treatments, shower gels, and lip balm. Each test samples were analyzed in duplicate using the validated method. Quality control (QC) samples were spiked with THC, CBD and CBN and internal standards in each of matrices.

\section{Results and discussion}

\subsection{Sample preparation}

Hemp seed oil based cosmetics contained relatively low polarity contents. Hence, relatively high polarity solvent such as isopropyl alcohol, ethyl alcohol and methyl alcohol were tested for cannabinoids extraction to reduce the interference of low polarity contents such as oils and fats. Among these solvents tested, methanol was found offered good extraction yield and less fat solubility. The followed ultrasonication assisted analytes releasing from samples. Satisfactory recovery rates were obtained using this simple and rapid sample preparation procedure without further cleaning and purification.

\subsection{Optimized separation and MS detection}

Conventional C18 columns could initially be used with an appropriate gradient. Therefore, LC

Table 1. MS/MS conditions for THC, CBD, and CBN.

\begin{tabular}{|c|c|c|c|c|c|c|c|c|}
\hline \multirow[t]{2}{*}{ Analytes } & \multirow{2}{*}{$\begin{array}{l}\text { Polarity } \\
\text { (ES) }\end{array}$} & \multirow{2}{*}{$\begin{array}{l}\text { Retention } \\
\text { Time (min) }\end{array}$} & \multicolumn{3}{|l|}{ Quantification ion } & \multicolumn{3}{|l|}{ Qualification ion } \\
\hline & & & $\begin{array}{l}\text { Precursor ion }> \\
\text { Product ion }(\mathrm{m} / \mathrm{z})\end{array}$ & C.V. (V) & C.E. $(e V)$ & $\begin{array}{l}\text { Precursor ion }> \\
\text { Product ion }(\mathrm{m} / \mathrm{z})\end{array}$ & C.V. (V) & C.E. $(\mathrm{eV})$ \\
\hline THC & + & 3.82 & $315>193^{*}$ & 40 & 20 & $315>259$ & 40 & 15 \\
\hline CBD & + & 2.34 & $315>193 *$ & 40 & 20 & $315>259$ & 40 & 15 \\
\hline CBN & + & 3.42 & $311>223^{*}$ & 30 & 15 & $311>241$ & 30 & 18 \\
\hline THC $-\mathrm{d}_{3}$ & + & 3.81 & $318>196$ & 40 & 15 & & & \\
\hline CBD- $d_{3}$ & + & 2.33 & $318>196$ & 40 & 15 & & & \\
\hline $\mathrm{CBN}-\mathrm{d}_{3}$ & + & 3.40 & $314>223$ & 30 & 15 & & & \\
\hline
\end{tabular}

Abbreviations: C.V., cone voltage; C.E., collision energy. 
separation was evaluated on Shiseido CAPCELL PAK C18 column $(2.7 \mu \mathrm{m}, 4.6 \times 150 \mathrm{~mm})$ and Xbridge BEH Shield RP18 column through isocratic and gradient elutions with mobile phases such as methanol and acetonitrile system. The results found that Xbridge BEH Shield RP18 column with solvent system contained $10 \mathrm{mM}$ ammonium formate provided adequate separation. The retention time (RT) for CBD, THC, and CBN was 2.44, 3.98, and $3.57 \mathrm{~min}$, respectively (Fig. 1). Total run time was 13 minutes in gradient mode. The mass spectrometer was in positive ESI mode. THC and CBD were isomers with the same monoisotope mass of
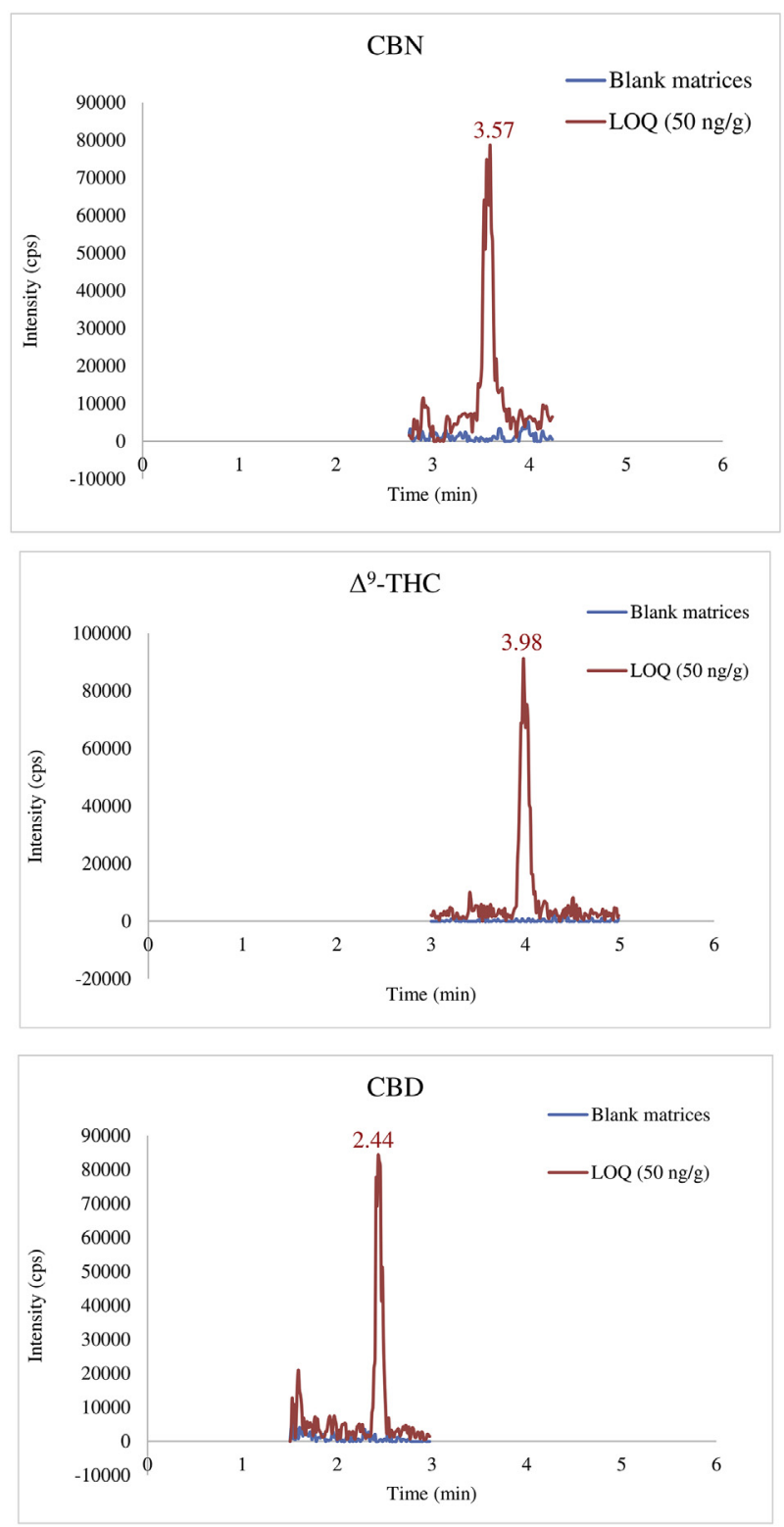

Fig. 1. Chromatograms for blank matrices (dash) and spiked sample at limit of quantification $50 \mathrm{ng} / \mathrm{g}$ (solid).
314.22 Dalton (Da) and showed an identical precursor to product ion transitions $(315 \rightarrow 193$ and 259, Fig. 2).

\subsection{Method validation}

\subsubsection{Accuracy, precision, and recovery}

Precision and accuracy data were summarized in Table 2. The coefficient of variation of QC samples was less than $10 \%$ of nominal concentrations for THC, CBD, and CBN. In most samples, accuracies were within $15 \%$ and $C V$ were less than $10 \%$ (ranged between 4.4 and 8.7\% for CBD, 3.2 and 9.3\% for CBN, 1.8 and $9.0 \%$ for THC). Similar results were seen with other matrices of essential oil, shampoo, shower gel, and lip balm. The intra-day recoveries ranged from $79-113 \%$ for $\mathrm{CBD}, 87-106 \%$ for $\mathrm{CBN}$, and $84-114 \%$ for THC (Table 2). The obtained results demonstrated the analytical method for the determination of THC, CBD, and CBN in hemp oil based cosmetics was validated in this work.

\subsubsection{Limits of quantification (LOQs)}

Limit of quantification (LOQs) levels were established for each cannabinoid. The LOQs in this study was found to be $50 \mathrm{ng} / \mathrm{g}$ for THC, CBN, and CBD. Precision and accuracy at this concentration level was determined to be satisfactory (Fig. 1).

\subsubsection{Linearity of calibration}

Standard curves were made in triplicate for each concentration of THC, CBD, and CBN. Good linearity was achieved over the concentration of 1$50 \mathrm{ng} / \mathrm{mL}$ with the application of a weighting factor $(1 / x)$. The correlation coefficient values were $r \geq 0.999$ for THC, $r \geq 0.998$ for both CBN and CBD.

\subsubsection{Matrix effects}

Matrix effect is due to the presence of coeluting matrix compounds that affect analyte ionizations leading to notable errors in quantification, and affects accuracy in LC-MS/MS method, unless adequately corrected or minimized. The use of internal standard is one of the most suitable for a reliable correction. Five matrix of cosmetics including lotion, essential oil, shampoo, shower gel, and lip balm were tested in this study, and the matrix effect was defined as the response ratio between analytes in matrix extract and analytes in solvent at the concentration of $0.5 \mu \mathrm{g} / \mathrm{g}$. The results showed in Fig. 3 that signal suppression was observed higher in lotion than in essential oil, shampoo and lip balm. The use of internal standard correction observed better and satisfied results in most tested samples. In essential oil matrix (Fig. 2B), 

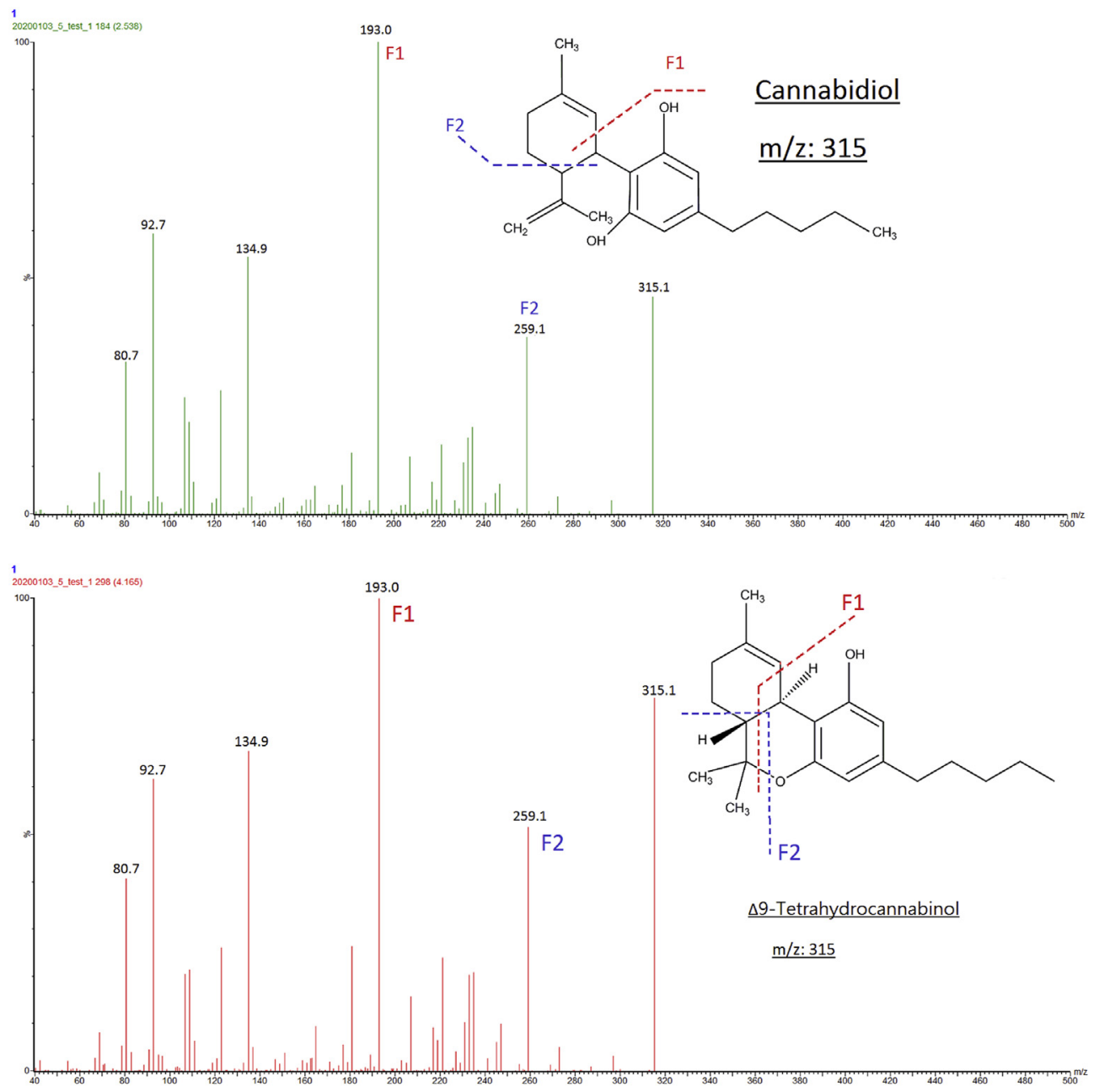

Fig. 2. Fragments spectra of standards CBD (A) and THC (B).

internal standard correction presented few negative effects. This may due to the complicate formula of essential oil and the higher content of solvents in essential oil products which may affect sample extraction. Consequently, the use of isotopically labeled internal standards was highly recommended for the analysis of cosmetic products.

\subsection{Surveillance results of cosmetics}

According to regulations for the control of cosmetic hygiene, cosmetics are defined as products designed for topical use, such as moisturizers, deodorants, and makeup. A surveillance study consisted of 90 cosmetic samples was conducted. All of them claimed containing hemp seed oil or hemp seed extract as ingredient. Most of them were leaveon products (44 samples) including lotions and creams. Others were essential oils (20 samples), hair-care products (10 samples), rinse-off products (10 samples), and lipstick products (6 samples).
Samples were collected between 2018 and 2020. Collection criteria of cosmetic samples in this study were ingredients labelled with "hemp seed oil" or "Cannabis sativa seed oil" as key words, or "CBD" or "Hemp" as specific product name. The test results showed 22 samples were found of THC (Table 3). The detected concentrations ranged between 0.063 and $1777 \mu \mathrm{g} / \mathrm{g}$. Among them 11 samples $(6,4,1$ in leave-on, essential oil, and lipstick samples, respectively) were found THC concentrations above $10 \mu \mathrm{g} / \mathrm{g}$ which was the legal level in most of regulations such as EU, Canada, and Taiwan. Thirty four samples were detected of CBD ranged between 0.47 and $37,217 \mu \mathrm{g} / \mathrm{g}$, and 5 samples were detected of CBN ranged between 2.22 and $25.17 \mu \mathrm{g} / \mathrm{g}$. In leaveon products, an average level of CBD was obtained as high as $7,720 \mu \mathrm{g} / \mathrm{g}$. Nineteen samples were found contained both THC and CBD. The present and concentration of THC and/or CBD in cosmetics in this study showed that there was no specific relation between them. Although the qualitative 
Table 2. Intra- and inter-day precision and accuracy results in different sample type.

\begin{tabular}{|c|c|c|c|c|c|c|c|c|c|c|c|c|c|c|c|c|c|}
\hline \multirow[t]{3}{*}{ Sample type } & \multirow[t]{2}{*}{$\begin{array}{l}\text { Spiked } \\
\text { level (ng/g) }\end{array}$} & \multicolumn{8}{|c|}{ Intra-day $(n=5)$} & \multicolumn{8}{|c|}{ Inter-day $(n=15)$} \\
\hline & & \multicolumn{2}{|l|}{50} & \multicolumn{2}{|l|}{100} & \multicolumn{2}{|l|}{250} & \multicolumn{2}{|l|}{500} & \multicolumn{2}{|l|}{50} & \multicolumn{2}{|l|}{100} & \multicolumn{2}{|l|}{250} & \multicolumn{2}{|l|}{500} \\
\hline & Analyte & $\begin{array}{l}\text { REC* } \\
(\%)\end{array}$ & $\begin{array}{l}\mathrm{CV}^{*} \\
(\%)\end{array}$ & $\begin{array}{l}\text { REC } \\
(\%)\end{array}$ & $\begin{array}{l}\mathrm{CV} \\
(\%)\end{array}$ & $\begin{array}{l}\text { REC } \\
(\%)\end{array}$ & $\begin{array}{l}\mathrm{CV} \\
(\%)\end{array}$ & $\begin{array}{l}\text { REC } \\
(\%)\end{array}$ & $\begin{array}{l}\mathrm{CV} \\
(\%)\end{array}$ & $\begin{array}{l}\text { REC } \\
(\%)\end{array}$ & $\begin{array}{l}\mathrm{CV} \\
(\%)\end{array}$ & $\begin{array}{l}\text { REC } \\
(\%)\end{array}$ & $\begin{array}{l}\mathrm{CV} \\
(\%)\end{array}$ & $\begin{array}{l}\text { REC } \\
(\%)\end{array}$ & $\begin{array}{l}\mathrm{CV} \\
(\%)\end{array}$ & $\begin{array}{l}\text { REC } \\
(\%)\end{array}$ & $\begin{array}{l}\mathrm{CV} \\
(\%)\end{array}$ \\
\hline \multirow[t]{3}{*}{ Lotion } & CBD & 98.80 & 7.14 & 87.73 & 4.43 & 87.03 & 8.67 & 113.47 & 7.87 & 101.50 & 8.71 & 91.92 & 7.46 & 90.85 & 8.31 & 104.00 & 8.57 \\
\hline & CBN & 90.20 & 8.42 & 86.70 & 7.84 & 92.43 & 4.13 & 95.37 & 4.52 & 92.27 & 7.69 & 90.75 & 9.33 & 94.87 & 5.91 & 92.55 & 5.13 \\
\hline & THC & 106.54 & 7.00 & 87.23 & 5.31 & 84.17 & 4.70 & 106.68 & 7.47 & 110.63 & 8.66 & 94.68 & 8.77 & 88.88 & 6.36 & 98.08 & 8.50 \\
\hline \multirow[t]{3}{*}{ Essential oil } & CBD & 92.60 & 5.37 & 97.40 & 5.92 & 88.27 & 6.04 & 98.67 & 3.91 & 99.96 & 9.19 & 95.81 & 5.65 & 91.38 & 6.26 & 97.14 & 5.72 \\
\hline & $\mathrm{CBN}$ & 91.12 & 7.94 & 92.34 & 5.01 & 96.57 & 4.25 & 101.95 & 4.34 & 91.53 & 5.04 & 89.85 & 5.92 & 97.30 & 4.85 & 98.71 & 5.43 \\
\hline & THC & 114.04 & 4.48 & 107.72 & 7.17 & 93.35 & 3.45 & 105.92 & 3.41 & 111.61 & 6.47 & 103.51 & 6.09 & 95.43 & 6.47 & 98.60 & 6.75 \\
\hline \multirow[t]{3}{*}{ Shampoo } & CBD & 86.38 & 4.36 & 84.55 & 3.45 & 82.51 & 4.15 & 100.06 & 3.01 & 90.63 & 7.10 & 91.06 & 8.45 & 88.91 & 8.61 & 95.52 & 9.92 \\
\hline & $\mathrm{CBN}$ & 96.74 & 6.64 & 100.61 & 7.73 & 95.28 & 5.05 & 99.96 & 3.61 & 91.82 & 5.79 & 93.38 & 9.35 & 97.60 & 4.62 & 101.21 & 3.54 \\
\hline & THC & 90.90 & 5.95 & 102.65 & 6.06 & 92.92 & 2.20 & 108.84 & 1.90 & 97.41 & 7.71 & 101.48 & 6.12 & 93.31 & 5.23 & 101.06 & 6.28 \\
\hline \multirow[t]{3}{*}{ Shower gel } & CBD & 86.56 & 2.95 & 79.23 & 4.59 & 84.77 & 8.68 & 95.14 & 5.86 & 92.06 & 6.85 & 88.03 & 8.75 & 89.57 & 8.35 & 94.10 & 6.66 \\
\hline & $\mathrm{CBN}$ & 92.04 & 6.35 & 88.22 & 5.30 & 94.88 & 6.44 & 102.56 & 3.29 & 83.55 & 9.91 & 85.55 & 7.44 & 90.34 & 6.34 & 98.00 & 6.69 \\
\hline & THC & 99.94 & 8.94 & 93.92 & 8.91 & 92.51 & 1.77 & 104.74 & 6.66 & 106.01 & 7.78 & 97.11 & 5.90 & 95.27 & 6.29 & 100.64 & 6.28 \\
\hline \multirow[t]{3}{*}{ Lip balm } & CBD & 100.68 & 6.06 & 92.26 & 5.33 & 91.85 & 5.01 & 101.61 & 8.42 & 101.65 & 7.24 & 95.12 & 5.59 & 93.04 & 5.95 & 96.78 & 8.51 \\
\hline & $\mathrm{CBN}$ & 106.08 & 9.31 & 97.19 & 2.79 & 102.77 & 3.21 & 102.12 & 5.52 & 104.46 & 9.82 & 98.65 & 7.49 & 97.50 & 6.07 & 104.68 & 7.42 \\
\hline & THC & 98.12 & 3.34 & 95.89 & 2.95 & 90.87 & 3.93 & 103.71 & 2.75 & 102.40 & 6.30 & 97.79 & 3.41 & 93.95 & 5.61 & 98.02 & 5.57 \\
\hline
\end{tabular}

${ }^{*} \mathrm{REC}$, recovery; $\mathrm{CV}$, coefficient of variation.
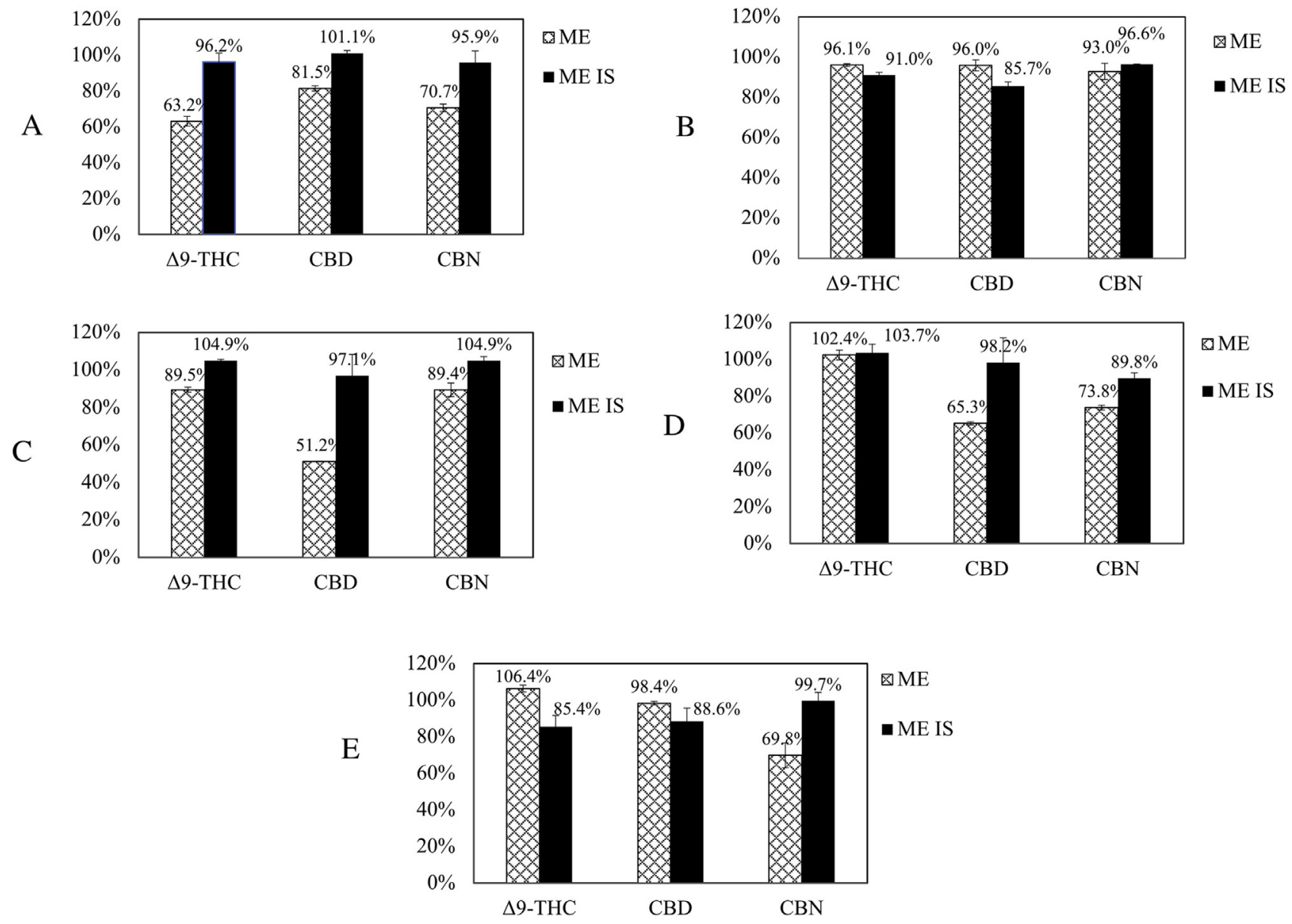

Fig. 3. Average matrix effects (ME, presented as recovery) for (A) lotion, (B) essential oil, (C) shampoo, (D) shower gel and (E) lip balm samples, before and after correction with internal standards (ME IS). 
Table 3. CBD, CBN and THC concentrations detected in cosmetics.

\begin{tabular}{lllll}
\hline Analyte & sample type & Number of samples & Concentration Range $(\mu \mathrm{g} / \mathrm{g})$ & Average Conc. $(\mu \mathrm{g} / \mathrm{g})$ \\
\hline CBD & Leave-on & 16 & $0.71-37,217$ & 7,720 \\
& Essential oil & 15 & $0.47-1,474$ & - \\
& Hair & 0 & - & - \\
& Rinse-off & 0 & - & 761 \\
THC & Lip & 3 & $1.03-1,184$ & 468 \\
& Leave-on & 9 & $0.18-1,777$ & 25.33 \\
& Essential oil & 10 & $0.063-83.06$ & - \\
& Hair & 0 & - & - \\
& Rinse-off & 0 & - & 17.63 \\
CBN & Lip & 3 & $0.095-27.79$ & 23.81 \\
& Leave-on & 1 & $23.81-23.81$ & 25 \\
& Essential oil & 2 & $24.81-25.17$ & \\
& Hair & 0 & - & 4.35 \\
\hline
\end{tabular}

characterization of chemical phynotype in Cannabis sativa L. was based on the THC/CBD ratio [23]. The amounts of cannabinoids varied in hemp-seed based cosmetics might be due to the variation of ingredients from plants cultured on various climate condition, cultivation location, genetic variability and harvesting time [24]. It was suggested that cannabinoids contribute to the chemical variabilities in the final products [25]. The identification of other minor cannabinoids might be another approach to better understand the chemical profile of these hemp-based cosmetics.

Label accuracy of cannabinoid-based cosmetics was also an issue to be concerned. The labeling accuracy of CBD showed 13 of 34 CBD detected samples claimed to contain CBD (e.g., "Herbal Fracture CBD", "CBD 750 mg", "CBD LIP BALM", "CBD DAY CREAM", "CBD SERUM" and "CBD DAILY SOOTHING SERUM"). The concentration range of CBD in CBD claimed sample was between 10.9 and $37,217 \mu \mathrm{g} / \mathrm{g}$, among them 7 articles also detected THC over $10 \mu \mathrm{g} / \mathrm{g}$. Also, four of the 13 CBD claimed products did not specify how much CBD they contained. And in the 9 that did, only six had a CBD concentration within $10 \%$ of the amount listed on their labels. Of the 4 products that claimed to contain CBD but did not indicate the amount of it, CBD detected range was between 10.90 and $57.70 \mu \mathrm{g} / \mathrm{g}$. The consumption of those undisclosed content of CBD products were for medical use or for other purpose remained to be elucidated. This developed method was successfully applied for the quantitative analysis of cannabinoids in commercial cosmetics products for a large range of matrix.

\section{Conclusion}

A presented method for the qualitative and quantitative determination of several cannabinoids including $\mathrm{CBD}, \mathrm{CBN}$, and THC, the main cannabinoids in hemp seed oil-based cosmetics, proved to be specific and selective. This validated method was applied into a surveillance consisted of 90 commercial cosmetics. In most of countries, the use of hemp seed oil as raw material in cosmetics was permitted as long as the product content of THC was below $10 \mu \mathrm{g} / \mathrm{g}$. The examination result concluded that of the 90 products, $41 \%$ (37/90) contained cannabinoids (15 CBD only, 3 THC only, 19 both), though only $35 \%$ (13/37) claimed to contained CBD. A high ratio of products analyzed contained THC or cannabinoids, which were undisclosed on the label. The claimed amounts of cannabinoids versus the actual amounts were discovered to have $67 \%$ accurately labeled (6/9). Moreover, $50 \%(11 / 22)$ of THC detected samples were found to have noncompliance THC concentration over $10 \mu \mathrm{g} / \mathrm{g}$. Though the sample size for this report is small, one should also consider the possibility that a product containing these substances may have both cosmetic and medical uses. Future work will include not only researches to cover more types of matrix of products, but also deeper investigations to other potential cannabinoids (analogues/derivatives) in hemp seed oil based cosmetics. The developed method for the quantification of cannabinoids was validated and surveillance reports could be used as a reference for administration to protect cosmetics product safety.

\section{References}

[1] United Nations Office on Drug and Crime. Recommended methods for the identification and analysis of cannabis and cannabis products: Manual for Use by national drug analysis laboratories. United nations publication; 2009.

[2] Callawa JC. Hempseed as a nutritional resource: An overview. Euphytica 2004;140:65-72. 
[3] Mikulcova V, Kasparkova V, Humpolicek P, Bunkova L. Formulation, characterization and properties of hemp seed oil and its emulsions. Molecules 2017;22:700.

[4] Dunford NT. 2-Hemp and flaxseed oil: Properties and applications for use in food. In: Talbot G, editor. Specialty oils and fats in food and nutrition. 1st ed. Cambridge: Woodhead Publishing; 2015. p. 39-63.

[5] Hazekamp A, Fischedick JT, Díez ML, Lubbe A, Ruhaak RL. Chemistry of Cannabis. In: Liu HW, Mander L, editors. Comprehensive Natural Products II. 1st ed. Oxford: Elsevier; 2010. p. 1033-84.

[6] Acosta E. Bioavailability of nanoparticles in nutrient and nutraceutical delivery. Curr Opin Colloid Interface Sci 2009; 14:3-15.

[7] Sun Y, Xia Z, Zheng J, Qiu P, Zhang L, McClements DJ, et al. Nanoemulsion-based delivery systems for nutraceuticals: Influence of carrier oil type on bioavailability of pterostilbene. J Funct Foods 2015;13:61-70.

[8] Raikos V, Ranawana V. Designing emulsion droplets of foods and beverages to enhance delivery of lipophilic bioactive components-a review of recent advances. Int J Food Sci Technol 2017;52:68-80.

[9] Callaway J, Schwab U, Harvima I, Halonen P, Mykkänen O, Hyvönen $P$, et al. Efficacy of dietary hempseed oil in patients with atopic dermatitis. J Dermatolog Treat 2005;16:87-94.

[10] Lodén M. Role of topical emollients and moisturizers in the treatment of dry skin barrier disorders. Am J Clin Dermatol 2003;4:771-88.

[11] Fichna J, Bawa M, Thakur GA, Tichkule R, Makriyannis A, McCafferty D-M, et al. Cannabinoids alleviate experimentally induced intestinal inflammation by acting at central and peripheral receptors. PLoS ONE 2014;9:e109115.

[12] Mounessa JS, Siegel JA, Dunnick CA, Dellavalle RP. The role of cannabinoids in dermatology. J Am Acad Dermatol 2017; 77:188-90.

[13] Gavazzoni Dias MF. Hair cosmetics: An overview. Int J Trichology 2015;7:2-15.

[14] Campos AC, Moreira FA, Gomes FV, Del Bel EA, Guimarães FS. Multiple mechanisms involved in the largespectrum therapeutic potential of cannabidiol in psychiatric disorders. Philos Trans R Soc Lond B Biol Sci 2012;367:3364-78.

[15] Grigoryev A, Savchuk S, Melnik A, Moskaleva N, Dzhurko J, Ershov M, et al. Chromatography-mass spectrometry studies on the metabolism of synthetic cannabinoids JWH-018 and
JWH-073, psychoactive components of smoking mixtures. J Chromatogr B 2011;879:1126-36.

[16] Citti C, Pacchetti B, Vandelli MA, Forni F, Cannazza G. Analysis of cannabinoids in commercial hemp seed oil and decarboxylation kinetics studies of cannabidiolic acid (CBDA). J Pharm Biomed Anal 2018;149:532-40.

[17] Molnar A, Lewis J, Doble P, Hansen G, Prolov T, Fu S. A rapid and sensitive method for the identification of delta9-tetrahydrocannabinol in oral fluid by liquid chromatography-tandem mass spectrometry. Forensic Sci Int 2012;215: 92-6.

[18] Roth N, Moosmann B, Auwärter V. Development and validation of an LC-MS/MS method for quantification of Delta 9-tetrahydrocannabinolic acid A (THCA-A), THC, CBN and CBD in hair. J Mass Spectrom 2013;48:227-33.

[19] Lebel P, Waldron KC, Furtos A. Rapid determination of 24 synthetic and natural cannabinoids for LC-MS-MS screening in natural products and drug inspection applications. LCGC 2015;13:8-14.

[20] Palazzoli F, Citti C, Licata M, Vilella A, Manca L, Zoli M, et al. Development of a simple and sensitive liquid chromatography triple quadrupole mass spectrometry (LC-MS/ MS) method for the determination of cannabidiol (CBD), $\Delta 9$ tetrahydrocannabinol (THC) and its metabolites in rat whole blood after oral administration of a single high dose of CBD. J Pharm Biomed Anal 2018;150:25-32.

[21] Leson G, Pless P, Grotenhermen F, Kalant H, ElSohly MA. Evaluating the impact of hemp food consumption on workplace drug tests. J Anal Toxicol 2001;25:691-8.

[22] Meng Q, Buchanan B, Zuccolo J, Poulin M-M, Gabriele J, Baranowski DC. A reliable and validated LC-MS/MS method for the simultaneous quantification of 4 cannabinoids in 40 consumer products. PLoS ONE 2018;13:e196396.

[23] Thomas BF, ElSohly MA. Chapter 1: The Botany of Cannabis sativa L. In: Thomas BF, ElSohly MA, editors. The analytical chemistry of Cannabis. Elsevier; 2016. p. 1-26.

[24] Menezes MMT, Andrade JF, Oliveira M, Tristão H, Saczk A, Okumura L. Analysis of $\delta 9-$ THC in cosmetics by high performance liquid chromatography with UV-Vis detection. Brazilian J Ana Chem 2012;2:341-4.

[25] Citti C, Linciano P, Panseri S, Vezzalini F, Forni F, Vandelli MA, et al. Cannabinoid Profiling of Hemp Seed Oil by Liquid Chromatography Coupled to High-Resolution Mass Spectrometry. Front Plant Sci 2019;10:120. 